\title{
COMPARAÇÃO DO ESTOQUE DE C ESTIMADO EM PASTAGENS E VEGETAÇÃO NATIVA DE CERRADO
}

\section{Comparison of the estimated $C$ stock in pastures and native Cerrado vegetation}

Jussara dos Santos Rosendo

Profa. Dra. da Faculdade de Ciências Integradas do Pontal-UFU, Ituiutaba-MG, Brasil

jussara@pontal.ufu.br

Roberto Rosa

Prof. Dr. do Instituto de Geografia-UFU. Bolsista CNPq.

rrosa@ufu.br

RESUMO: As mudanças climáticas constituem uma ameaça para o meio ambiente e para o desenvolvimento sustentável no mundo. São causadas pelo aumento do efeito estufa acima do nível desejável, principalmente devido aos gases $\mathrm{CO}_{2}, \mathrm{CH}_{4}$ e $\mathrm{N}_{2} \mathrm{O}$ na atmosfera, sendo o $\mathrm{CO}_{2}$ o mais abundante. Os solos são reconhecidamente importantes sumidouros de gases do efeito estufa, especialmente para o $\mathrm{CO}_{2}$. O principal objetivo deste artigo foi comparar o estoque de carbono armazenado em solos sob pastagens e solos sob vegetação nativa de cerrado, na bacia hidrográfica do rio Araguari- MG. A metodologia da pesquisa envolveu as seguintes etapas: seleção das áreas ocupadas com pastagens e Cerrado; coleta de amostras de solo para determinação do estoque de carbono e análises de laboratório. Com apoio de imagens do sensor TM/Landsat5, foram coletadas amostras de solo em campo sob pastagem de brachiaria melhorada, pastagem de brachiaria degradada e cerrado, nas profundidades de 0 a $20 \mathrm{~cm}$ e 20 a $40 \mathrm{~cm}$. Os resultados alcançados mostraram que a pastagem melhorada para a camada de 0 a $20 \mathrm{~cm}$ apresentou estoque de carbono de 43,92 $\mathrm{Mg} \mathrm{C}^{-1}$, enquanto o cerrado 38,05 $\mathrm{Mg} \mathrm{C}^{-1}$ e a pastagem degradada 34,63 $\mathrm{Mg} \mathrm{C}$ ha $^{-1}$, ao passo que à profundidade $20 \mathrm{a} 40 \mathrm{~cm}$, a pastagem melhorada atingiu $33,5 \mathrm{Mg} \mathrm{C} \mathrm{ha-1}^{-1}$ o cerrado 26,80 $\mathrm{Mg} \mathrm{C}$ ha $^{-1}$ e a pastagem degradada 27,51 Mg C ha' $\mathrm{Mg}^{-1}$ o que permite concluir que pastagens bem estabelecidas e manejadas, podem contribuir no aumento da taxa de sequestro de carbono pelo solo. Entretanto, a falta de correção do solo, de adubação de manutenção, de controle de processos erosivos e de manejo adequado, com excesso de lotação (sobrepastejo) têm levado a um estágio de degradação das pastagens cultivadas, o que compromete a capacidade das mesmas de seqüestrar carbono.

Palavras-chave: estoque de $\mathrm{C}$ nos solos, pastagens, Cerrado.

ABSTRACT: The climate changes are considered a threat to the environment and for the sustainable development in the world. They are caused by the increase in the greenhouse effect above the desirable level, mainly due to $\mathrm{CO}_{2}, \mathrm{CH}_{4}$ and $\mathrm{N}_{2} \mathrm{O}$ in the atmosphere, even though $\mathrm{CO}_{2}$ is the most abundant. The soils are recognized as important greenhouse gases sinks, especially for $\mathrm{CO}_{2}$. The main objective of this paper was to compare the carbon stock stored in soils under pasture and soils under native cerrado vegetation, in Araguari River basin in Minas Gerais state. The research methodology involved the following steps: selection of the areas occupied by pastures and cerrado; collecting soil samples for carbon to define the carbon stock and laboratory analysis. With the support of TM/Landsat5 sensor, soil samples were collected in the field under improved pastures of brachiaria, degraded pastures of brachiaria and cerrado, at 0 to $20 \mathrm{~cm}$ and 20 to 40 $\mathrm{cm}$ depths. The results reached showed that the improved pasture to the layer from 0 to $20 \mathrm{~cm}$ showed a carbon stock of 43,92 $\mathrm{Mg} \mathrm{C}^{-1}$, while cerrado showed 38,05 $\mathrm{Mg} \mathrm{C}^{-1}$ and the degraded pasture 34,63 $\mathrm{Mg} \mathrm{C} \mathrm{ha}^{-1}$, while the depth from 20 to $40 \mathrm{~cm}$, the improved pasture reached 33,5 $\mathrm{Mg} \mathrm{C}^{-1}$, the cerrado 
26,80 $\mathrm{Mg} \mathrm{C} \mathrm{ha}^{-1}$ and the degraded pasture $27,51 \mathrm{Mg} \mathrm{C} \mathrm{ha}^{-1}$, what allow us to conclude that pastures well established and managed can contribute to the increasing of the rate of carbon sequestration in the soil. However, the lack of soil remediation, fertilizer maintenance, erosion control and proper management, with overcrowding (overgrazing) has led the pastures to a stage of degradation, which compromises the ability of those to sequester carbon.

Keyworks: C stock in the soils, pastures, Cerrado.

\section{INTRODUÇÃO}

O clima da Terra muda em função das variações de sua órbita em torno do Sol, de erupções vulcânicas e concentrações atmosféricas de gases do efeito estufa. O processo de intervenção humana nos ciclos naturais de mudanças climáticas, no entanto, aumentou desde o período da Revolução Industrial. As mudanças vêm se aprofundando e manifestam-se de diversas formas, com destaque para as causas associadas ao aquecimento global, como maior freqüência e intensidade de eventos climáticos extremos assim como alterações no regime de chuvas.

As mudanças climáticas constituem uma ameaça para o meio ambiente e para o desenvolvimento sustentável no mundo. São causadas pelo aumento do efeito estufa acima do nível desejável, principalmente devido aos gases dióxido de carbono $\left(\mathrm{CO}_{2}\right)$, metano $\left(\mathrm{CH}_{4}\right)$ e óxido nitroso $\left(\mathrm{N}_{2} \mathrm{O}\right)$ na atmosfera, sendo o $\mathrm{CO}_{2}$ o mais abundante. Estes gases contribuem para uma maior absorção da radiação solar, resultando no aumento da temperatura na atmosfera. As causas do aquecimento recente, embora sem um consenso científico, se devem ao aumento nos níveis de gases de efeito estufa (GEE), especialmente com constatações sobre o aumento da concentração de dióxido de carbono na atmosfera.

O efeito estufa é um processo natural ocasionado pelo acúmulo de gases na atmosfera, formando uma barreira que aprisiona a radiação infravermelha. Esse fenômeno é o que mantém o planeta aquecido e possibilita a vida na Terra. Entretanto, quando a concentração desses gases é excessiva, mais radiação fica retida na atmosfera, provocando o aquecimento global.

$\mathrm{O} \mathrm{CO}_{2}$ atmosférico é oriundo da respiração dos animais e vegetais, da decomposição e queima das substâncias orgânicas e da atividade dos oceanos. Posteriormente, volta ao solo através da fotossíntese das plantas terrestres e dos plânctons oceânicos. O C na Terra está essencialmente na forma de compostos orgânicos e carbonatos ou sob a forma de gás $\left(\mathrm{CO}_{2}\right)$ na atmosfera. $\mathrm{O}$ ciclo do $\mathrm{C}$ consiste na transferência deste elemento, por meio de queima, respiração, reações químicas, para a atmosfera ou para o mar e a sua reintegração na matéria orgânica.

$\mathrm{O}$ estoque de $\mathrm{C}$ de um solo sob vegetação natural representa o balanço dinâmico entre a adição de material vegetal morto e a perda pela decomposição ou mineralização (SCHOLES et al., 1997 apud CHAVES; FARIAS, 1998). A qualidade do $C$ da vegetação depende muito do clima, do tipo de vegetação e da fertilidade do solo.

Os relatórios do IPCC reconhecem que as concentrações globais de gases têm crescido fundamentalmente como resultado de atividades humanas. Informam ainda, que o aumento na concentração de gás carbônico se deve essencialmente ao uso de combustíveis fósseis e às mudanças no uso da terra, sendo essas significativas, mas com uma contribuição inferior ao do uso de combustíveis fósseis. A concentração do mais relevante gás de efeito estufa antropogênico, o $\mathrm{CO}_{2}$, variou de $280 \mathrm{ppm}$ no período pré-industrial para aproximadamente $390 \mathrm{ppm}$ atualmente.

Enquanto nos países de clima temperado a maior fonte do $\mathrm{CO}_{2}$ é a oxidação de combustíveis fósseis (veículos, sistemas de aquecimento e de refrigeração, indústrias), que geram os maiores volumes globais anuais de $\mathrm{CO}_{2}$, nas regiões tropicais a maior fonte de $\mathrm{CO}_{2}$ se deve aos desmatamentos e as mudanças de uso da terra. Nas atividades agrícolas, a liberação do $\mathrm{CO}_{2}$ incorporado no material vegetal ocorre durante as queimadas e durante o revolvimento do solo, com entrada de oxigênio, que permitem a mineralização ou a oxidação da matéria orgânica. Além disso, há emissão de $\mathrm{CO}_{2}$ resultante da combustão de restos vegetais na superfície do solo.

Soc. \& Nat., Uberlândia, ano 24 n. 2, 359-376, mai/ago. 2012 
Estima-se que o Brasil possui cerca de 100 milhões de hectares de pastagens cultivadas. Só no Bioma Cerrado ocupam uma área de 54,1 milhões de hectares, ou seja, $26,4 \%$ do bioma (SANO et. al., 2010), em sua maior parte do gênero das brachiarias, das quais aproximadamente metade apresenta algum grau de degradação. O país é hoje o maior exportador de carne bovina do mundo, e tal atividade ocupa a maior área do território brasileiro, portanto, deve-se conciliar o aumento da produção de carne a partir de sistemas com baixa emissão de $\mathrm{CO}_{2}$, ou seja, que seqüestre $\mathrm{CO}_{2}$ no solo, ou que seja capaz de reduzir o impacto sobre o aquecimento global.

Face ao exposto, este trabalho tem como objetivo comparar o estoque de carbono armazenado em solos sob pastagens e solos cobertos pela vegetação nativa de cerrado, na bacia hidrográfica do rio Araguari - MG.

\section{FUNDAMENTAÇÃO TEÓRICA}

As discussões a cerca das mudanças climáticas têm levado várias organizações a propor regras de conduta, com a finalidade de minimizar a emissão dos gases causadores do efeito estufa (GEEs). A redução dos GEEs é uma das metas do Protocolo de Kyoto. De acordo com IPCC (2007), o sequestro de carbono pelos solos é o mecanismo responsável pelo maior potencial de mitigação de gases de efeito estufa (GEE), com uma estimativa de contribuição de $89 \%$.

Os três principais processos responsáveis pelo seqüestro de $\mathrm{C}$ nos solos são a humificação, agregação e sedimentação, e os processos responsáveis pelas perdas de C no solo são: a erosão, decomposição volatilização e lixiviação (MACHADO, 2005).

Singh e Lal (2005) salientaram que "There are two principal options of reducing the rate of enrichment of the tropospheric concentration of greenhouse gases: (i) reducing emissions and (ii) sequestering carbon (C)". Esta citação demonstra a importância que os solos assumem na conjuntura atual, uma fase em que a preocupação com o futuro da humanidade atinge as mais diversas esferas (econômicas, sociais, ambientais, políticas, etc.), para as quais a mitigação das possíveis mudanças climáticas globais deixou de ser tarefa apenas dos países desenvolvidos.
Globalmente, há de duas a três vezes mais carbono nos solos, em relação ao estocado na vegetação, e cerca do dobro em comparação com a atmosfera. Portanto, manejos inadequados podem mineralizar a matéria orgânica e transferir grandes quantidades de gases do efeito estufa para a atmosfera (CERRI, 2007).

$\mathrm{O}$ estoque de $\mathrm{C}$ no solo, na camada até 30 $\mathrm{cm}$, é de cerca de $800 \mathrm{Pg} \mathrm{C}$, ou seja, quase a mesma quantidade armazenada na atmosfera $730 \mathrm{Pg}$ (CERRI et al. 2006). Entretanto, é pertinente salientar que os solos são ecossistemas frágeis.

O carbono orgânico total (COT) ou a matéria orgânica do solo (MOS) encontram-se entre um conjunto de variáveis químicas, físicas e biológicas, que, acompanhadas ao longo do tempo, são capazes de detectar as alterações da qualidade do solo em função do manejo (MIELNICZUCK, 2008). Além da MOS ser um importante reservatório de carbono, possui uma rápida troca com o $\mathrm{CO}_{2}$ atmosférico. Isso a torna importante fonte potencial e/ou absorvedor de gases de efeito estufa ao longo da escala de tempo de interesse humano (SCHIMEL, 1995 apud TRUMBORE e TORN, 2003).

As perdas de carbono em pastagem podem ser mínimas ou até ter ganhos em comparação com a vegetação natural (CORRAZA, et. al., 1999). O manejo de pastagens tem sido citado como a segunda mais importante tecnologia agrícola disponível para a mitigação das mudanças climáticas globais (FAO, 2009). De acordo com FAO (2009), as pastagens cobrem, aproximadamente, $30 \%$ da superfície da Terra, e ocupam cerca de 3,4 bilhões de hectares, dos quais, $73 \%$ são afetados pela degradação dos solos, além do fato de que cerca de 1 bilhão de pessoas dependem dessas áreas para subsistência.

Estima-se que as pastagens armazenam até $30 \%$ do carbono do solo no mundo. O potencial para sequestrar carbono através da melhoria no manejo destas pastagens é significativo em virtude da grande extensão em área que elas ocupam (FAO, 2009).

O IPCC estima que um melhor manejo das pastagens em países como o Brasil criaria um potencial líquido de estocagem de carbono de $0,80 \mathrm{Mg}$ há $^{-1}$ ano $^{-1}$, indicando que as pastagens oferecem maior potencial de seqüestro de carbono do que as florestas e culturas agrícolas. 
FAO (2009) apontou que algumas melhorias no manejo das pastagens incluem: restauração da matéria orgânica dos solos, redução da erosão, eliminação das queimadas e evitar sobrepastejo.

De acordo com EMBRAPA (2004), no Cerrado, a introdução de pastagens de Brachiaria spp. foi uma prática comum em áreas anteriormente ocupadas pela vegetação, e, atualmente, cobrem uma vasta área do Brasil tropical. Dados preliminares revelaram que se estas pastagens forem bem manejadas, podem se manter produtivas por vários anos, e os estoques de $\mathrm{C}$ no solo podem exceder aqueles sob a vegetação original do cerrado.

As práticas de manejo do solo podem causar diferenças nas taxas de mineralização da matéria orgânica. Mudanças no $\mathrm{C}$ do solo das pastagens podem ocorrer em função do manejo, além de fatores ambientais, como, por exemplo, pastejo, fogo, fertilização, além da conversão das pastagens em cultura. Processos erosivos podem ocasionar perda de $\mathrm{C}$ no solo das pastagens pela redução da produtividade do solo erodido (FAO, 2009).

As queimadas são práticas frequentes para a limpeza das áreas ocupadas por pastagens. Extensas áreas são queimadas todo ano em diversas partes do globo. Estima-se que 700 milhões de hectares sejam queimados globalmente, ocorrendo uma perda de cerca de 1,6 Gt C por ano (FAO, 2009). Nesse sentido, medidas de controle de queimadas devem ser adotadas, no intuito de reduzir/limitar a sua intensidade e frequência, objetivando minimizar as conseqüências das emissões de carbono e outras emissões de gases, além de reduzir a degradação do solo e da vegetação.

Boddey et al. (2001) explicaram que o carbono depositado no solo, sob qualquer tipo de vegetação, origina-se de duas fontes:

- Serrapilheira, ou liteira, originada dos tecidos senescentes da vegetação, entre os quais se incluem folhas e galhos senescentes, ou da morte de toda a planta, inclusive árvores. Este material, em grande parte, decompõe-se na superfície do solo, e, uma parte se integra a ele, sobretudo nas camadas mais superficiais, mediante a ação da macro e mesofauna;

-Raízes senescentes.
Entende-se por manejo do solo todas as operações efetuadas em uma área, como sua abertura, a correção da acidez superficial e da alta saturação de alumínio subsuperficial, a adubação corretiva e de manutenção, os sistemas de preparo do solo e a rotação de culturas, incluindo-se as práticas culturais, a pastagem e a floresta (RESCK, 1996 apud BODDEY, 2001). Além das descritas anteriormente, Dias Filho (2004) ainda inseriu como práticas de manejo, o sistema de pastejo e o controle de plantas invasoras. O referido autor orientou, também, que o objetivo principal das práticas de manejo, desde o seu estabelecimento, é otimizar a produção de forma sustentável.

Dias Filho (2004) considerou que uma pastagem poderia ser considerada degradada ou em dregradação quando:

(...) a "degradação agrícola", isto é, a capacidade da pastagem para produzir economicamente (do ponto de vista agropecuário) estaria temporariamente diminuída ou inviabilizada, devido à pressão competitiva exercida pelas plantas daninhas sobre o capim, causando, portanto, queda acentuada na capacidade de suporte da pastagem (DIAS FILHO, 2004, p. 251).

Ou então,

(...) "degradação biológica", pois a capacidade de área em sustentar a produção vegetal estaria comprometida. Nessa situação extrema de produtividade da pastagem, houve "reversão" no processo de sucessão vegetal para o estádio de solo exposto, via de regra causada por práticas inadequadas de manejo, como altas pressões de pastejo, uso excessivo de fogo, etc., as quais provocam danos severos à parte aérea e subterrânea da vegetação, erosão do solo e queda acentuada da fertilidade e da matéria orgânica (DIAS FILHO, 2004, p. 251).

Levando-se em consideração o fato de que as pastagens produtivas podem aumentar os estoques de carbono no sistema além dos níveis da vegetação

Soc. \& Nat., Uberlândia, ano 24 n. 2, 359-376, mai/ago. 2012 
nativa, e sabendo-se que existem mais de 50 milhões de ha de pastagens na região do Cerrado, das quais $50 \%$ podem ser consideradas degradadas, há que se levar em conta que a recuperação destas terá um grande impacto do ponto de vista da produção animal. Concomitantemente, o aumento das áreas de pastagens produtivas poderá contribuir, significativamente, para a melhoria dos parâmetros hídricos e para a redução da erosão nestas regiões, além da diminuição do efeito estufa pelo sequestro de C (BODDEY et al. 2001).

\section{LOCALIZAÇÃO E CARACTERIZAÇÃO DA ÁREA DE ESTUDO}

A área escolhida para este estudo foi à bacia do Rio Araguari-MG em virtude de apresentar vastas áreas ocupadas com agricultura e pastagens, merecendo destaque a produção econômica dos municípios inseridos na bacia. Compreende grande parte da Mesorregião do Triângulo Mineiro e Alto Paranaíba, na porção oeste do estado de Minas Gerais, Brasil. Está situada entre as coordenadas geográficas $18^{\circ} 20^{\prime} \mathrm{e}$ $20^{\circ} 10^{\prime}$ de latitude sul e $46^{\circ} 00^{\prime}$ e $48^{\circ} 50$ > de longitude oeste de Greenwich, ocupando uma área de 20.186 $\mathrm{km}^{2}$. Fazem parte da bacia, os seguintes municípios: Araguari, Araxá, Campos Altos, Ibiá, Indianópolis, Iraí de Minas, Nova Ponte, Patrocínio, Pedrinópolis, Perdizes, Pratinha, Rio Paranaíba, Sacramento, Santa Juliana, São Roque de Minas, Serra do Salitre, Tapira, Tupaciguara, Uberaba e Uberlândia (Figura 1).

Figura 1: Localização da área de estudo:

a) no Brasil, b) em Minas gerais; c) Limite da bacia do Rio Araguari nos municípios nela contidos

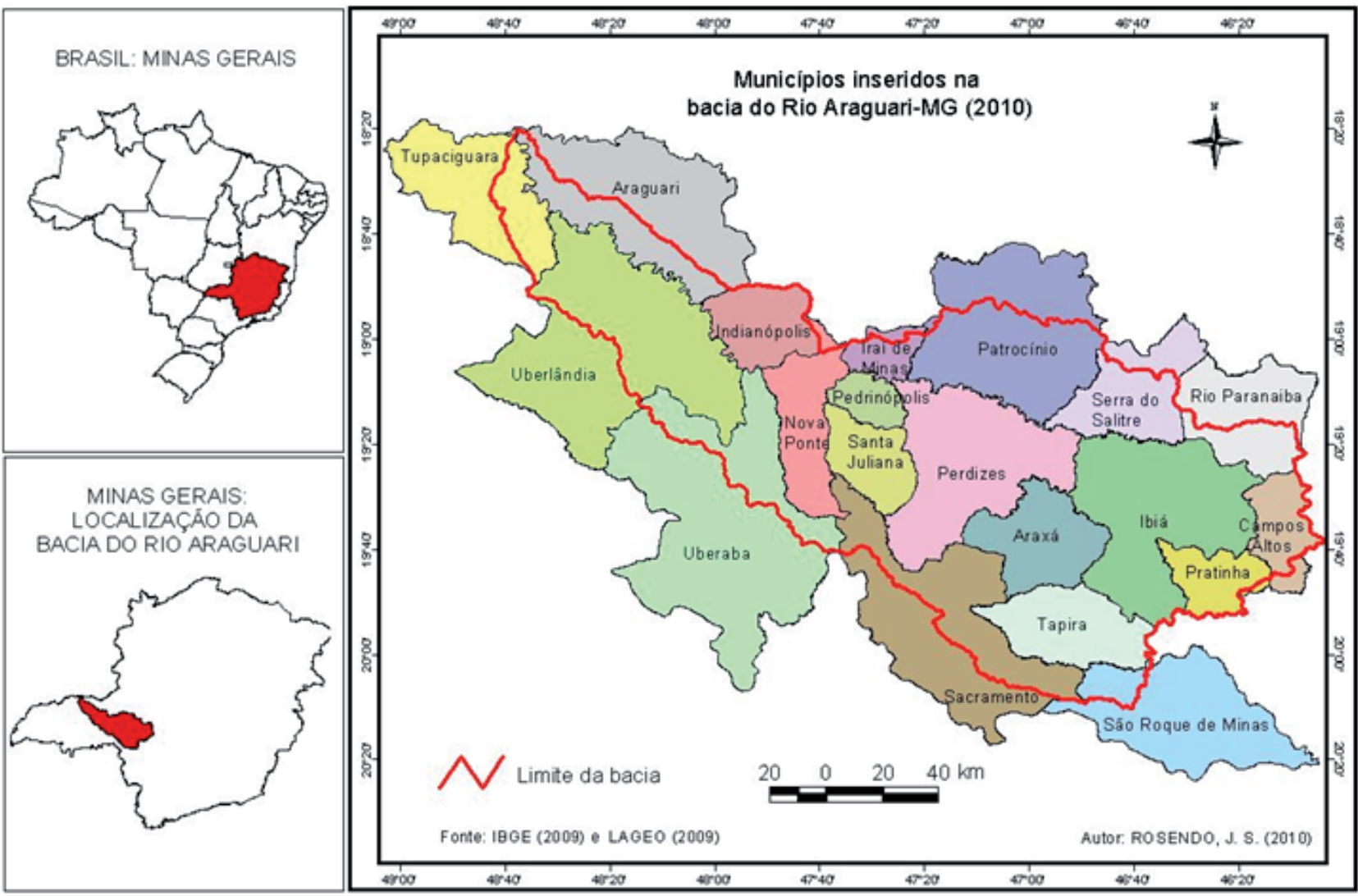

A economia da maioria dos municípios da bacia se baseia na agropecuária, ou seja, na criação de gado e produção de grãos. Contudo, a localização ge- ográfica favoreceu a inserção de alguns municípios na economia nacional, tornando a região um entreposto comercial na distribuição de produtos agropecuários e 
Comparação do estoque de C estimado em pastagens e vegetação nativa de Cerrado Jussara dos Santos Rosendo, Roberto Rosa

industrializados. A maior parte da área da bacia (76\%) esta situada entre as cotas altimétricas de 850 a 1150 metros (Figura 2). Mais de 90\% da área possui declividade do terreno menor do que $20 \%$ (Figura 3). Em $49 \%$ da área predominam os solos do tipo latossolo vermelho-amarelo. O clima da bacia é caracterizado por uma estação seca de maio a setembro e uma estação chuvosa de outubro a abril, com precipitação anual em torno de $1500 \mathrm{~mm}$ e temperatura média anual de $21,9^{\circ} \mathrm{C}$ (ROSA, et al. 2004).

Figura 2: Mapa Hipsométrico da bacia do Rio Araguari

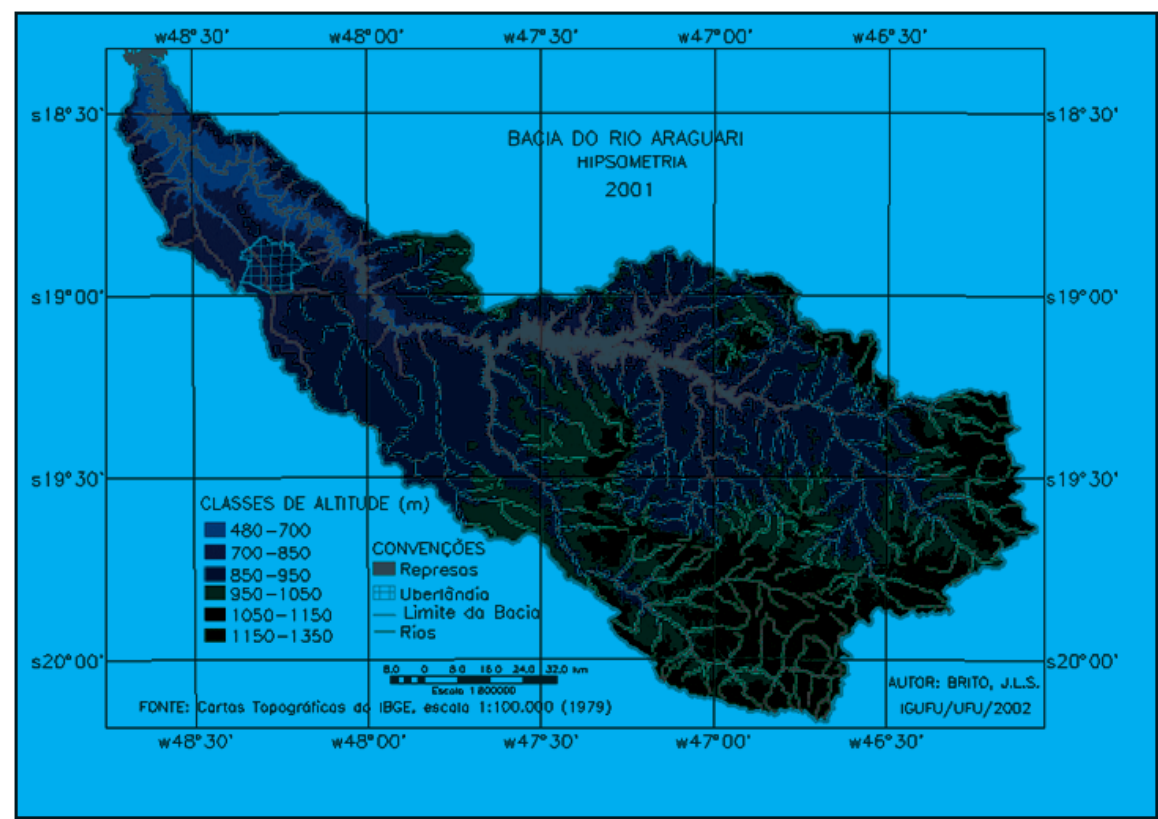

Fonte: Fonte: Rosa et al. (2004).

Figura 3: Mapa de declividade da bacia do Rio Araguari

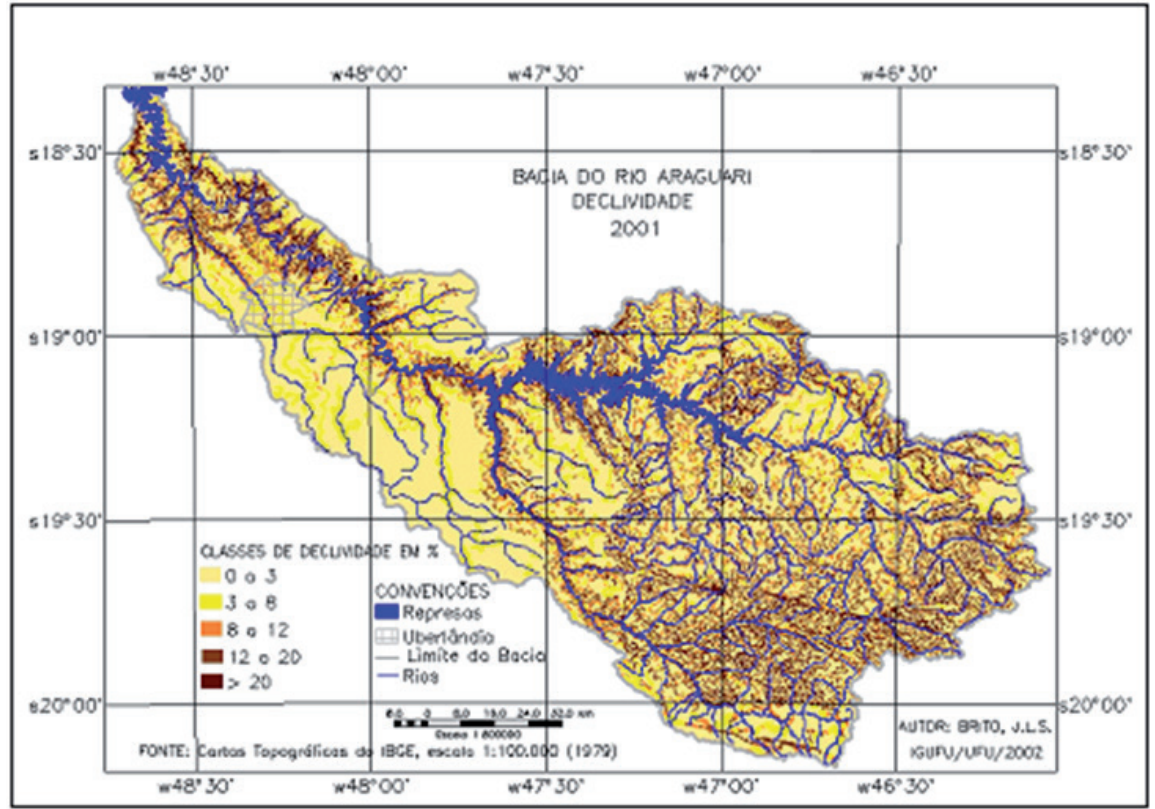

Fonte: Rosa et al. (2004).

Soc. \& Nat., Uberlândia, ano 24 n. 2, 359-376, mai/ago. 2012 


\section{MATERIAIS E MÉTODO}

Os alvos escolhidos para este estudo foram: vegetação nativa de cerrado (cerrado - CER), pastagem de brachiaria melhorada (pastagem melhorada PME) e pastagem de brachiaria degradada (pastagem degradada - PDE). As pastagens foram escolhidas por ocuparem a maior área da bacia hidrográfica do Rio Araguari, cerca de $30 \%$ (Figura 4), como apontado por Rosendo (2010), e por apresentar um elevado potencial de seqüestro de carbono, segundo o IPCC.

Figura 4: Mapa de uso da terra e cobertura vegetal natural da bacia do Rio Araguari-MG em 2009

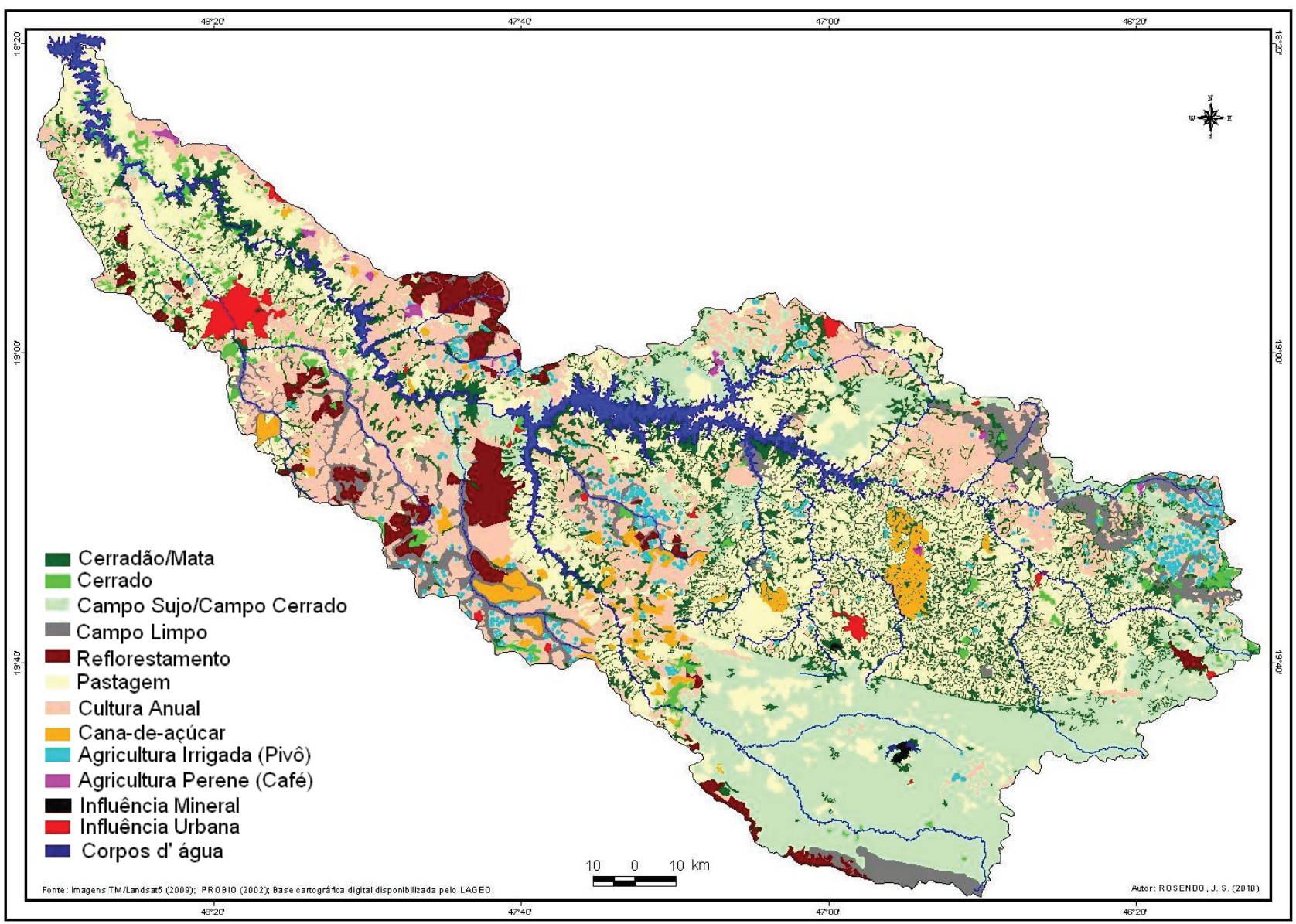

Com intuito de minimizar outros efeitos que influenciam no estoque de carbono dos solos, as amostras foram selecionadas de tal forma que a distância entre elas não ultrapassasse $50 \mathrm{~km}$, procurando minimizar a influência de fatores pedológicos, topográficos e climáticos. Em função disso, as coletas das amostras concentraram-se na porção noroeste da bacia (Figura 5), por apresentarem características hipsométricas, de declividade e tipo de solos (Latossolo) semelhantes. 


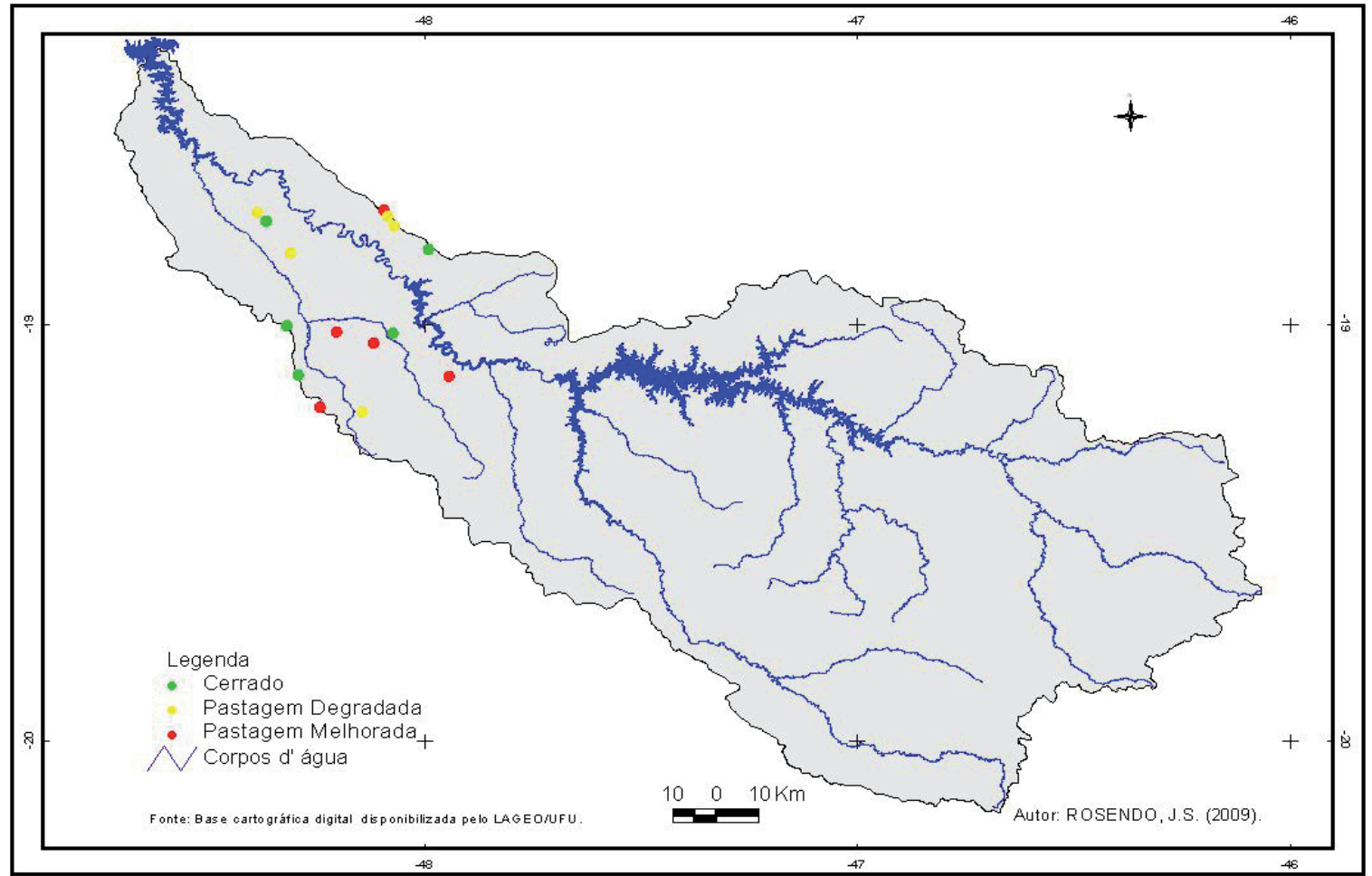

Para a quantificação do estoque de carbono há necessidade de se estabelecer a profundidade do solo a que se refere o estoque. Para a presente pesquisa, as amostras de solo foram obtidas nas profundidades de 0-20 e 20-40 cm por dois motivos: o primeiro deles é que grande quantidade de carbono é armazenado nessas camadas e o segundo está relacionado ao fato de que as atividades agrícolas têm forte influência nessa profundidade. Na tabela 1 e na Figura 6 estão representados os tipos de uso, as coordenadas e as datas das coletas.

Tabela 1: Localização das áreas amostradas para coleta de solos.

\begin{tabular}{cccc}
\hline \multirow{2}{*}{ Uso/Amostras } & \multicolumn{2}{c}{ Coordenadas } & \multirow{2}{*}{ Data da coleta } \\
\cline { 2 - 3 } & $\mathbf{m E}$ & $\mathbf{m N}$ & \\
\hline Cerrado/CER1 & 184.759 & 7.916 .054 & $17 / 6 / 2009$ \\
Cerrado/CER2 & 782.391 & 7.896 .138 & $18 / 6 / 2009$ \\
Cerrado/CER3 & 785.068 & 7.882 .993 & $18 / 6 / 2009$ \\
Cerrado/CER4 & 808.179 & 7.893 .739 & $19 / 6 / 2009$ \\
Cerrado/CER5 & 777.621 & 7.924 .146 & $20 / 6 / 2009$ \\
\hline Pastagem Melhorada/PME1 & 807.215 & 7.925 .317 & $17 / 6 / 2009$ \\
Pastagem Melhorada/PME2 & 789.987 & 7.874 .420 & $18 / 6 / 2009$ \\
Pastagem Melhorada/PME3 & 803.392 & 7.891 .192 & $18 / 6 / 2009$ \\
Pastagem Melhorada/PME4 & 794.375 & 7.894 .446 & $18 / 6 / 2009$ \\
Pastagem Melhorada/PME5 & 190.470 & 7.882 .440 & $17 / 6 / 2009$ \\
\hline Pastagem Degradada/PDE1 & 807.268 & 7.925 .173 & $17 / 6 / 2009$ \\
Pastagem Degradada/PDE2 & 800.254 & 7.873 .174 & $18 / 6 / 2009$ \\
Pastagem Degradada/PDE3 & 808.179 & 7.893 .739 & $19 / 6 / 2009$ \\
Pastagem Degradada/PDE4 & 783.450 & 7.915 .688 & $20 / 6 / 2009$ \\
Pastagem Degradada/PDE5 & 776.298 & 7.925 .631 & $20 / 6 / 2009$ \\
\hline
\end{tabular}

Org. dos autores.

Soc. \& Nat., Uberlândia, ano 24 n. 2, 359-376, mai/ago. 2012 
Figura 6: Áreas de Cerrado (CER), pastagem de brachiaria melhorada (PME) e pastagem de brachiaria degradada (PDE) onde foram coletas as amostras de sol.

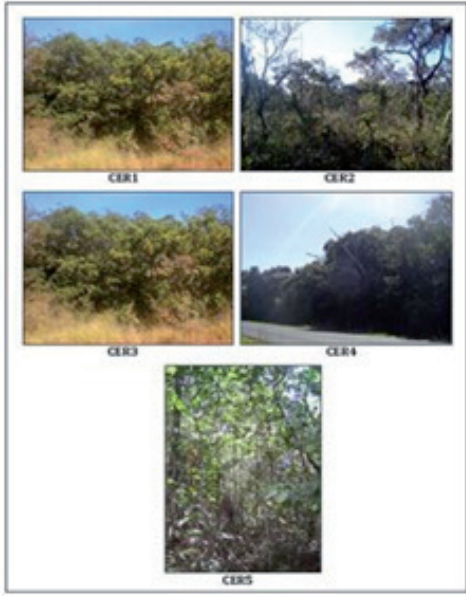

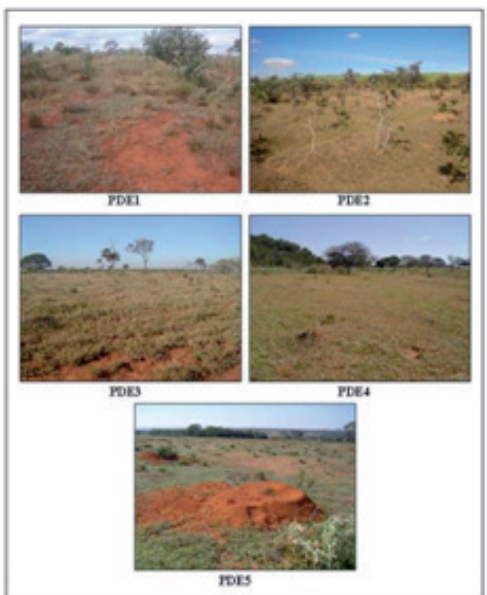

Org. dos autores.

Depois de definidas as áreas, a segunda etapa da metodologia consistiu na realização de trabalhos de campo para coleta das amostras de solo, com auxílio de imagem de satélite TM/Landsat5, mapa de solos e receptor GPS, foram percorridas as áreas (previamente selecionadas) durante o mês de junho de 2009.

Para cada categoria de análise definida, foram obtidas amostras de solo com trado tipo holandês, em que foram coletadas cinco amostras simples de maneira aleatória em cada categoria de uso/cobertura vegetal, por profundidade, as quais foram combinadas para formar uma amostra composta por camada de solo amostrada.

A amostra composta foi obtida da seguinte forma: selecionaram-se cinco áreas diferentes com vegetação de Cerrado, cada uma denominada como CER1, CER2, CER3, CER4 e CER5 (representando o mesmo tipo de cobertura, ou seja, Cerrado, no entanto em locais diferentes da bacia). Em cada uma dessas amostras (ex. CER1) foram realizadas 5 coletas de solo com trado holandês, na mesma área, e misturadas para formar uma amostra composta que representasse, por exemplo, o CER1 nas profundidades de análise 0 a 20 e 20 a $40 \mathrm{~cm}$. Como foram definidos 3 tipos de usos diferentes $($ Cerrado $=$ CER; pastagem melhorada $=$ PME e pastagem degrada $=$ PDE), o processo análogo de coleta foi realizado para a pastagem melhorada
(PME) e pastagem degradada (PDE).

Todo o solo coletado na amostra composta foi embalado e identificado para a determinação da densidade aparente, granulometria e Carbono Orgânico Total (COT). A densidade do solo foi obtida por meio do peso seco (g) de amostras retiradas em ambas profundidades, com o auxílio de um anel volumétrico de metal de volume previamente conhecido $(81,54$ $\mathrm{cm}^{3}$ ). Esse procedimento de coleta das amostras de solo foi efetuado nas mesmas áreas onde foram extraídas as amostras para análises do COT e textura. A textura foi calculada segundo método da pipeta conforme demonstrado em Embrapa (1997). O pH foi determinado em água $(1: 2,5)$ por potenciometria, sendo a acidez trocável $(\mathrm{Al} 3+)$ extraída com $\mathrm{KCl} 1$ $\mathrm{mol} / \mathrm{L}$ e quantificada por titulometria com hidróxido de sódio $0,025 \mathrm{~mol} / \mathrm{L}$, padronizado com biftalato de potássio (EMBRAPA, 1997)

O COT do solo foi determinado pela oxidação da matéria orgânica com $\mathrm{K}_{2} \mathrm{Cr}_{2} \mathrm{O}_{7}$ em meio ácido, e o excesso de dicromato foi titulado com $\left(\mathrm{NH}_{4}\right)_{2} \mathrm{Fe}\left(\mathrm{SO}_{4}\right)_{2}$ (YEOMANS \& BREMNER, 1988). Na terceira etapa, procedeu-se com o cálculo do estoque de carbono $(\mathrm{Mg}$ $\mathrm{C} \mathrm{ha}^{-1}$ ), realizado para uma determinada profundidade, da seguinte maneira: 


$$
E s t C=\frac{\text { COtotal }^{*} D^{*} e}{10}
$$

Onde:

EstC $=$ estoque de carbono orgânico na camada estudada $\left(\mathrm{Mg} \mathrm{ha}^{-1}\right)$;

COtotal $=$ carbono orgânico total $\left(\mathrm{g} \mathrm{kg}^{-1}\right)$;

$\mathrm{D}=$ densidade aparente do solo da camada estudada $\left(\mathrm{g} \mathrm{cm}^{-3}\right)$;

$\mathrm{e}=$ espessura da camada estudada $(\mathrm{cm})$.

Por fim, para verificar tendências de acúmulo ou perda de C orgânico em comparação com o sistema de referência (vegetação natural), foi calculada a variação do estoque de $\mathrm{C}$ em relação à média dos teores de $\mathrm{C}$ da vegetação de cerrado (CER), ou seja, "delta" $\Delta$ EstC. O $\Delta$ EstC é calculado pela diferença entre os valores médios de estoque de $\mathrm{C}$ da vegetação nativa (CER) e os valores médios de estoque de $C$ nas pastagens.

\section{RESULTADOS E DISCUSSÃO}

Os resultados das análises para os teores de carbono, granulometria e densidade, realizadas em cada categoria de análise, podem ser observados nas Tabelas 2, 3 e 4. Estes dados mostram que as análises individuais apresentaram valores bem distintos entre si. A título de ilustração, cita-se o exemplo do CER1, que apresenta $722 \mathrm{gkg}^{-1}$ de argila, enquanto que CER2=243 $\mathrm{gkg}^{-1}, \mathrm{CER} 3=315 \mathrm{gkg}^{-1}, \mathrm{CER} 4=523$ $\mathrm{gkg}^{-1}$ e CER5=343 $\mathrm{gkg}^{-1}$. Em função disto, optou-se por trabalhar com os dados médios de cada categoria (Tabela 5).

Tabela 2: Estoques de $\mathrm{C}$, densidade, $\mathrm{pH}$ e granulometria das áreas de cerrado

(CER) para as profundidades 0 a 20 e 20 a $40 \mathrm{~cm}$.

\begin{tabular}{|c|c|c|c|c|c|c|c|}
\hline $\begin{array}{c}\text { Cerrado } \\
(0 \text { a } 20 \mathrm{~cm})\end{array}$ & $\begin{array}{c}\text { Densidade } \\
\left(\mathrm{g} \mathrm{cm}^{-3}\right)\end{array}$ & $\begin{array}{c}\text { Carbono } \\
\left(\mathrm{Mg} \mathrm{C} \mathrm{ha}^{-1}\right)\end{array}$ & pH & $\begin{array}{c}\text { Areia Grossa } \\
\left(\mathrm{g} \mathrm{kg}^{-1}\right)\end{array}$ & $\begin{array}{c}\text { Areia fina } \\
\left(\mathrm{g} \mathrm{kg}^{-1}\right)\end{array}$ & $\begin{array}{c}\text { Silte } \\
\left(\mathrm{g} \mathrm{kg}^{-1}\right)\end{array}$ & $\begin{array}{l}\text { Argila } \\
\left(\mathrm{g} \mathrm{kg}^{-1}\right)\end{array}$ \\
\hline CER1 & 1,01 & 44,82 & 4,94 & 90 & 151 & 37 & 722 \\
\hline CER2 & 1,27 & 31,45 & 4,48 & 501 & 230 & 26 & 243 \\
\hline CER3 & 1,30 & 34,17 & 4,55 & 323 & 332 & 30 & 315 \\
\hline CER4 & 1,24 & 42,38 & 4,58 & 205 & 179 & 93 & 523 \\
\hline CER5 & 1,11 & 37,41 & 4,61 & 283 & 346 & 28 & 343 \\
\hline Média & 1,19 & 38,05 & 4,63 & 280 & 248 & 43 & 429 \\
\hline Des_Pad & 0,11 & 4,97 & 0,18 & 152 & 88 & 28 & 193 \\
\hline \multicolumn{8}{|l|}{$\begin{array}{c}\text { Cerrado } \\
(20 \text { a } 40 \mathrm{~cm})\end{array}$} \\
\hline CER1 & 1,08 & 33,85 & 4,66 & 74 & 159 & 25 & 742 \\
\hline CER2 & 1,37 & 23,86 & 4,4 & 449 & 230 & 53 & 268 \\
\hline CER3 & 1,30 & 23,81 & 4,83 & 314 & 334 & 18 & 334 \\
\hline CER4 & 1,22 & 22,25 & 4,76 & 187 & 161 & 62 & 590 \\
\hline CER5 & 1,23 & 30,25 & 4,63 & 230 & 358 & 135 & 277 \\
\hline Média & 1,24 & 26,80 & 4,66 & 251 & 248 & 59 & 442 \\
\hline Des_Pad & 0,10 & 4,47 & 0,15 & 126 & 84 & 42 & 190 \\
\hline
\end{tabular}

Org. dos autores.

Soc. \& Nat., Uberlândia, ano 24 n. 2, 359-376, mai/ago. 2012 
Tabela 3: Estoques de C, densidade, $\mathrm{pH}$ e granulometria das áreas de pastagem melhorada (PME) para as profundidades 0 a 20 e 20 a $40 \mathrm{~cm}$.

\begin{tabular}{|c|c|c|c|c|c|c|c|}
\hline $\begin{array}{l}\text { Pastagem } \\
\text { Melhorada } \\
(0 \text { a } 20 \mathrm{~cm}) \\
\end{array}$ & $\begin{array}{c}\text { Densidade } \\
\text { (g cm-3) }\end{array}$ & $\begin{array}{c}\text { Carbono } \\
\text { (Mg C ha- } \\
\text { 1) }\end{array}$ & pH & $\begin{array}{c}\text { Areia Grossa } \\
\text { (g kg-1) }\end{array}$ & $\begin{array}{c}\text { Areia fina } \\
(\mathrm{g} \mathrm{kg}-1)\end{array}$ & $\begin{array}{c}\text { Silte } \\
\text { (g kg-1) }\end{array}$ & $\begin{array}{l}\text { Argila } \\
\text { (g kg-1) }\end{array}$ \\
\hline PME 1 & 1,23 & 42,48 & 5,25 & 75 & 249 & 18 & 658 \\
\hline PME 2 & 1,51 & 41,07 & 6,36 & 316 & 372 & 15 & 297 \\
\hline PME 3 & 1,02 & 49,33 & 5,35 & 129 & 51 & 85 & 735 \\
\hline PME 4 & 1,33 & 44,89 & 5,94 & 264 & 145 & 100 & 491 \\
\hline PME 5 & 1,54 & 41,83 & 5,55 & 324 & 251 & 13 & 412 \\
\hline Média & 1,33 & 43,92 & 5,69 & 222 & 214 & 46 & 519 \\
\hline Des_Pad & 0,19 & 2,99 & 0,41 & 101 & 109 & 38 & 160 \\
\hline \multicolumn{8}{|l|}{$\begin{array}{c}\text { Pastagem } \\
\text { Melhorada } \\
(20 \text { a } 40 \mathrm{~cm})\end{array}$} \\
\hline PME 1 & 1,16 & 30,71 & 4,58 & 68 & 219 & 22 & 691 \\
\hline PME 2 & 1,36 & 32,43 & 4,67 & 324 & 342 & 6 & 328 \\
\hline PME 3 & 1,19 & 37,76 & 5,26 & 103 & 38 & 9 & 850 \\
\hline PME 4 & 1,31 & 33,53 & 4,71 & 262 & 158 & 12 & 568 \\
\hline PME 5 & 1,41 & 31,30 & 5,05 & 324 & 242 & 73 & 361 \\
\hline Média & 1,29 & 33,15 & 4,85 & 216 & 200 & 24 & 560 \\
\hline Des_Pad & 0,10 & 2,50 & 0,26 & 110 & 100 & 25 & 197 \\
\hline
\end{tabular}

Tabela 4: Estoques de C, densidade, $\mathrm{pH}$ e granulometria das áreas de pastagem degradada (PDE) para as profundidades 0 a 20 e 20 a $40 \mathrm{~cm}$.

\begin{tabular}{|c|c|c|c|c|c|c|c|}
\hline $\begin{array}{c}\text { Pastagem } \\
\text { Degradada } \\
(0 \text { a } 20 \mathrm{~cm})\end{array}$ & $\begin{array}{l}\text { Densidade } \\
\left(\mathrm{g} \mathrm{cm}^{-3}\right)\end{array}$ & $\begin{array}{c}\text { Carbono } \\
\left(\mathrm{Mg} \mathrm{C} \mathrm{ha-1)}^{-1}\right)\end{array}$ & pH & $\begin{array}{c}\text { Areia Grossa } \\
\left(\mathrm{g} \mathrm{kg}^{-1}\right) \\
\end{array}$ & $\begin{array}{c}\text { Areia fina } \\
\left(\mathrm{g} \mathrm{kg}^{-1}\right) \\
\end{array}$ & $\begin{array}{c}\text { Silte } \\
\left(\mathrm{g} \mathrm{kg}^{-1}\right) \\
\end{array}$ & $\begin{array}{l}\text { Argila } \\
\left(\mathrm{g} \mathrm{kg}^{-1}\right) \\
\end{array}$ \\
\hline PDE 1 & 1,13 & 36,21 & 4,37 & 64 & 178 & 110 & 648 \\
\hline PDE 2 & 1,28 & 39,47 & 4,93 & 287 & 246 & 88 & 379 \\
\hline PDE 3 & 1,30 & 37,26 & 5,03 & 215 & 136 & 38 & 611 \\
\hline PDE 4 & 1,18 & 37,31 & 4,64 & 275 & 255 & 16 & 454 \\
\hline PDE 5 & 1,46 & 22,89 & 6,65 & 428 & 249 & 38 & 285 \\
\hline Média & 1,27 & 34,63 & 5,12 & 254 & 213 & 58 & 475 \\
\hline Des_Pad & 0,11 & 5,96 & 0,80 & 118 & 48 & 35 & 137 \\
\hline \multicolumn{8}{|l|}{$\begin{array}{c}\text { Pastagem } \\
\text { Degradada } \\
(20 \text { a } 40 \mathrm{~cm})\end{array}$} \\
\hline PDE 1 & 1,09 & 27,82 & 4,58 & 49 & 159 & 25 & 767 \\
\hline PDE 2 & 1,37 & 34,80 & 4,80 & 242 & 261 & 29 & 468 \\
\hline PDE 3 & 1,24 & 28,69 & 4,81 & 208 & 139 & 58 & 595 \\
\hline PDE 4 & 1,17 & 27,96 & 4,76 & 269 & 281 & 13 & 437 \\
\hline PDE 5 & 1,46 & 18,27 & 5,83 & 390 & 288 & 8 & 314 \\
\hline Média & 1,27 & 27,51 & 4,96 & 232 & 226 & 27 & 516 \\
\hline Des_Pad & 0,13 & 5,30 & 0,44 & 110 & 63 & 17 & 154 \\
\hline
\end{tabular}

Org. dos autores. 
$\mathrm{O}$ estoque médio de $\mathrm{C}$ do CER, PME e PDE presentes na bacia do Rio Araguari (Tabela 5) variou de 34,63 $\mathrm{Mg} \mathrm{C}$ ha $^{-1}$ (média da PDE) a 43,92 Mg C ha $^{-1}$ (média da PME), à profundidade 0 a $20 \mathrm{~cm}$. Para a profundidade de 20 a $40 \mathrm{~cm}$, o valor máximo obser- vado, 33,15 $\mathrm{Mg} \mathrm{C} \mathrm{ha}^{-1}$ diz respeito aos dados da PME, sendo o menor valor encontrado no CER, $26,80 \mathrm{Mg}$ $\mathrm{C} \mathrm{ha}^{-1}$, este, menor que a PDE, $27,51 \mathrm{Mg} \mathrm{C}^{-1}{ }^{-1}$, fato que chamou a atenção dos pesquisadores.

Tabela 5: Estoque de C (baseado nas médias) do CER (cerrado), PME (pastagem melhorada) e PDE (pastagem degradada) para as profundidades 0 a $20 \mathrm{~cm}$ e 20 a $40 \mathrm{~cm}$

\begin{tabular}{|c|c|c|c|c|}
\hline \multirow[b]{2}{*}{ Usos } & \multicolumn{2}{|c|}{$(0$ a $20 \mathrm{~cm})$} & \multicolumn{2}{|c|}{$(20$ a $40 \mathrm{~cm})$} \\
\hline & $\begin{array}{c}\text { Estoque C } \\
\left(\mathrm{Mg} \mathrm{ha}^{-1}\right)\end{array}$ & $\begin{array}{c}\text { Taxa de adição ou perda } \\
\text { de C }\left(\mathrm{Mg} \mathrm{C} \mathrm{ha}^{-1}\right) \\
\Delta \mathrm{EstC}\left(\mathrm{Mg} \mathrm{ha}^{-1}\right)\end{array}$ & $\begin{array}{c}\text { Estoque C } \\
\left(\mathrm{Mg} \mathrm{ha}^{-1}\right)\end{array}$ & $\begin{array}{c}\text { Taxa de adição ou } \\
\text { perda de C }\left(\mathrm{Mg} \mathrm{C} \mathrm{ha}^{-1}\right) \\
\Delta \text { EstC }\left(\mathrm{Mg} \mathrm{ha}^{-1}\right)\end{array}$ \\
\hline CER & 38,05 & - & 26,80 & - \\
\hline PME & 43,92 & 5,87 & 33,15 & 6,34 \\
\hline PDE & 34,63 & $-3,42$ & 27,51 & 0,70 \\
\hline
\end{tabular}

A partir da análise da Tabela 5, para a profundidade 0 a $20 \mathrm{~cm}$, observa-se que o estoque médio de $\mathrm{C}$ obedeceu a seguinte ordem: $\mathrm{PME}>\mathrm{CER}>\mathrm{PDE}$. Para a profundidade 20 a $40 \mathrm{~cm}$ houve mudança de comportamento, sendo PME $>$ PDE $>$ CER. Percebe-se por esses dados que a pastagem, se bem manejada, pode acumular mais $\mathrm{C}$ no solo que a vegetação natural.

Ao analisar os resultados dos estoques de C separadamente, para as subamostras da PDE, é possível perceber que os dados referentes a Tabela 4 apresentam um desvio padrão ( $\boldsymbol{\sigma}$ ) elevado de $5,96 \mathrm{e}$ $5,30 \mathrm{em} 0$ a 20 e 20 a $40 \mathrm{~cm}$, respectivamente, como conseqüência da PDE5 ter apresentado estoque de C

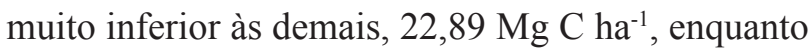
que as outras áreas compreenderam os seguintes valores PDE1=36,21 Mg Cha ${ }^{-1}$, PDE2 $=39,47 \mathrm{Mg} \mathrm{C}^{-1}$, PDE3=37,26 Mg C ha ${ }^{-1}$ e PDE4=37,31 $\mathrm{Mg} \mathrm{Cha}^{-1}$. O baixo estoque de $\mathrm{C}$ observado se deu em função da PDE5 apresentar maior nível de degradação que as outras pastagens degradadas, além de considerável área de solo exposto.

A degradação em pastagens está associada ao manejo inadequado, como a não utilização de técnicas como a rotação de pastagem, a falta de controle da lotação do pasto (superpastejo), a não incorporação de nutrientes no solo e a eventual ocorrência de queimadas. Ficou evidente que, em nenhuma das áreas de PDE, se recorre ao uso de adubação de manutenção.

Uma melhor análise dos estoques de carbono pode ser obtida quando se compara a variação obtida nas pastagens (melhorada e degradada) com o Cerrado nativo $(\triangle \mathrm{EstC})$, conforme pode ser observado na Tabela 5 e no Gráfico 1. Esse parâmetro permite avaliar se o solo está armazenando ou emitindo $\mathrm{C}-\mathrm{CO}_{2}$ para atmosfera (FORTIN et al., 1996; BAYER et al., 2000; ROCHA, 2000 apud NEVES et al., 2004).

Com esse objetivo, compararam-se os estoques totais de $\mathrm{C}$ existentes no CER, que representa a vegetação nativa, com as pastagens analisadas. Conforme apresentado no Gráfico 1 verifica-se que a quantidade de $\mathrm{C}$ na PDE foi substancialmente menor que no CER, indicando perda de C. Pode-se considerar que, a $\mathrm{PDE}$ atuou como fonte de $\mathrm{C}-\mathrm{CO}_{2}$ à atmosfera na profundidade 0 a $20 \mathrm{~cm}$, apesar da tendência de acúmulo de $\mathrm{C}$, embora de maneira muito discreta, na profundidade de 20 a $40 \mathrm{~cm}$.

Soc. \& Nat., Uberlândia, ano 24 n. 2, 359-376, mai/ago. 2012 
Gráfico 1: $\Delta$ EstC para os diferentes usos da terra presentes na bacia do Rio Araguari para as profundidades 0 a $20 \mathrm{~cm}$ e 20 a $40 \mathrm{~cm}$

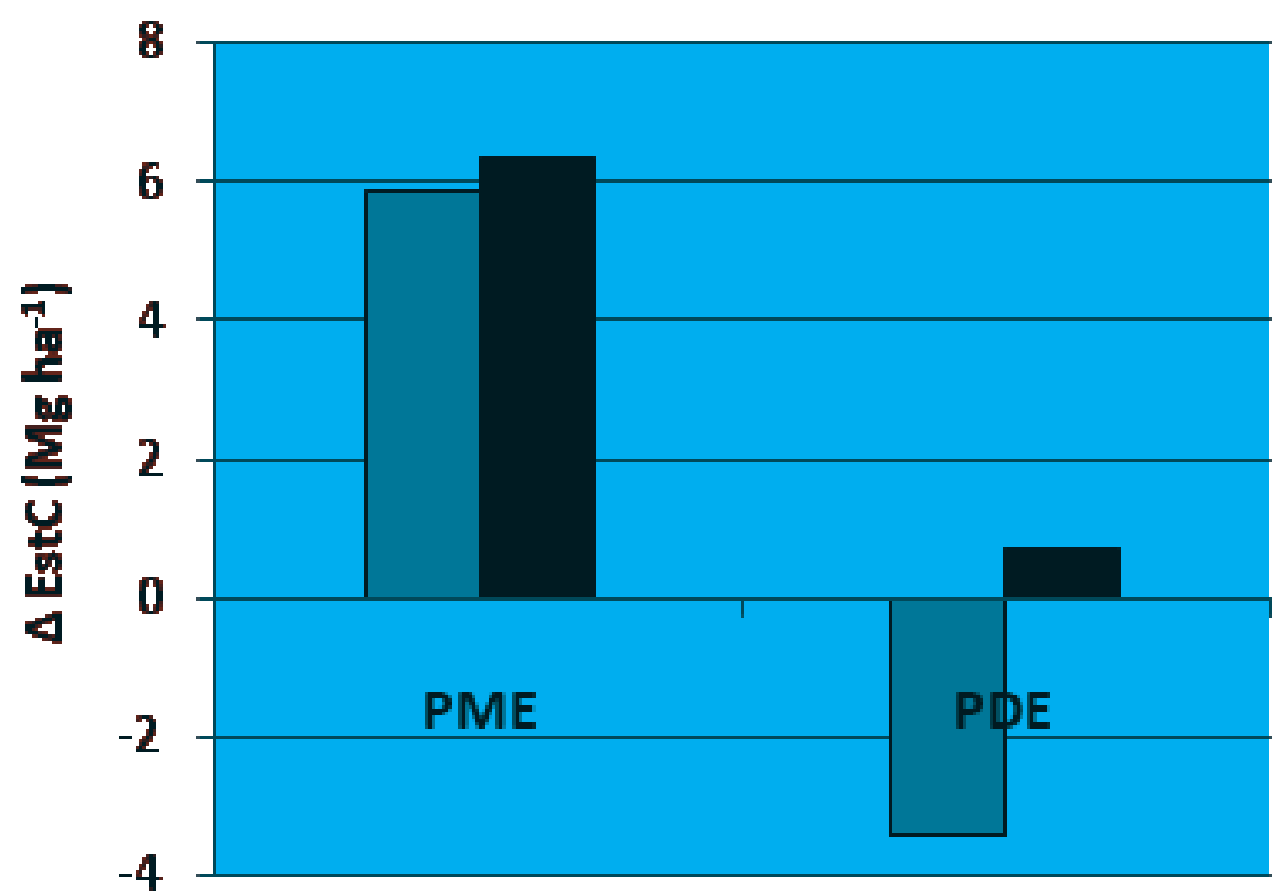

$\square 0-20 \mathrm{~cm} \quad \square 20-40 \mathrm{~cm}$

Em contrapartida, o teor de C estocado no solo pela PME foi superior ao do CER em ambas as profundidades, neste caso, a PME atuou como seqüestrador de C-CO $\mathrm{CO}_{2}$. Os resultados obtidos indicaram tendência consistente com a proposta de Lal et al. (1995) apud Corazza et al., (1999), bem como por Rangel e Silva (2007), ou seja, sistemas de manejo não perturbados podem acumular mais $\mathrm{C}$ que a vegetação natural. Os dados observados vão de acordo com mencionado por alguns autores, como Freixo et al. (2002) apud D' Andréia et al. (2004) e FAO (2010), ao afirmarem que a pastagem é considerada eficiente na manutenção do C orgânico no solo.

Vale mencionar que a PDE obteve apenas 8,98\% menos C estocado no solo que o CER (0 a 20 $\mathrm{cm})$. Esses valores chamam a atenção para o potencial das pastagens em estocar e manter o $\mathrm{C}$ no solo mesmo na ausência de práticas de manejo adequadas. Também permitem inferir que o incentivo à melhoria da qualidade das pastagens pode tornar-se uma alternativa para aumentar a produção de carne e potencializar o seqüestro de carbono pelo solo, contribuindo assim com a redução do efeito estufa.

A presente pesquisa confirmou o que Freitas et al. (2000) mostraram, ou seja, que as pastagens cultivadas e bem manejadas podem manter o nível do estoque orgânico nas camadas superficiais, equivalente ao estoque sob vegetação natural correspondente. O Quadro 1 mostra que as estimativas obtidas nesta análise aproximaram-se das realizadas por diversos autores em diferentes trabalhos. Tais valores foram utilizados para fins de comparação. 
Comparação do estoque de C estimado em pastagens e vegetação nativa de Cerrado Jussara dos Santos Rosendo, Roberto Rosa

Quadro 1: Estoques de C observados em pesquisas realizadas por diferentes autores e a comparação com dados observados nesta pesquisa (Mg C ha-1)

\begin{tabular}{|c|c|c|c|c|c|}
\hline Uso & cm & $\begin{array}{c}\text { Estoque de C } \\
(\mathrm{Mg} \mathrm{C} \mathrm{ha})\end{array}$ & Autores & $\begin{array}{c}\text { Esta } \\
\text { pesquisa } \\
0 \text { a } 20 \mathrm{~cm} \\
\end{array}$ & $\begin{array}{c}\text { Esta } \\
\text { pesquisa } \\
20 \text { a } 40 \mathrm{~cm}\end{array}$ \\
\hline \multirow{6}{*}{ Cerrado } & $0-20$ & 39,77 & $\begin{array}{c}\text { Boddey et al. (2001) apud } \\
\text { Corazza (1999) }\end{array}$ & \multirow{6}{*}{38,05} & \multirow{6}{*}{26,80} \\
\hline & $20-40$ & 30,09 & $\begin{array}{c}\text { Boddey et al. (2001) apud } \\
\text { Corazza (1999) }\end{array}$ & & \\
\hline & $0-20$ & 39,77 & D'Andréia et al. (2004) & & \\
\hline & $0-40$ & 23,21 & D'Andréia et al. (2004 & & \\
\hline & $0-20$ & 37,98 & $\begin{array}{l}\text { Corazza et al (1999) apud } \\
\text { D'Andréia et al. (2004) }\end{array}$ & & \\
\hline & $0-20$ & 35,10 & Neves et al. (2004) & & \\
\hline \multirow{7}{*}{ Pastagem** } & $0-20$ & 30,00 & Neves et al. (2004) & \multirow{7}{*}{43,92} & \multirow{7}{*}{33,15} \\
\hline & $20-40$ & 22,20 & Neves et al. (2004) & & \\
\hline & $0-20$ & 39,28 & $\begin{array}{l}\text { Boddey et al. (2001) apud } \\
\text { Rezende et al. (1999 }\end{array}$ & & \\
\hline & $20-40$ & 21,34 & $\begin{array}{l}\text { Boddey et al. (2001) apud } \\
\text { Rezende et al. (1999 }\end{array}$ & & \\
\hline & $0-20$ & 42,18 & $\begin{array}{c}\text { Boddey et al. (2001) apud } \\
\text { Corazza (1999) }\end{array}$ & & \\
\hline & $20-40$ & 32,59 & $\begin{array}{l}\text { Boddey et al. (2001) apud } \\
\text { Corazza (1999) }\end{array}$ & & \\
\hline & $0-20$ & 39,54 & $\begin{array}{l}\text { Boddey et al. (2001) apud } \\
\text { Rezende et al. (1999) }\end{array}$ & & \\
\hline \multirow{2}{*}{$\begin{array}{l}\text { Pastagem } \\
\text { Degradada }\end{array}$} & $0-20$ & 27,01 & $\begin{array}{l}\text { Boddey et al. (2001) apud } \\
\text { Rezende et al. (1999) }\end{array}$ & \multirow{2}{*}{34,63} & \multirow{2}{*}{27,51} \\
\hline & $20-40$ & 14,98 & $\begin{array}{l}\text { Boddey et al. (2001) apud } \\
\text { Rezende et al. (1999) }\end{array}$ & & \\
\hline
\end{tabular}

* Os autores não fizeram referência se a pastagem é melhorada ou não, por isso, optou-se pela citação apenas de "pastagem" em vez de "pastagem melhorada" ou "pastagem degradada".

Org. dos autores.

A Tabela 6 apresenta os índices de correlação calculados para a média dos estoques de $\mathrm{C}$ em relação aos valores médios de densidade, teor de areia, silte e argila presentes nos solos às profundidades de $0 \mathrm{a} 20$ $\mathrm{cm}$ e 20 a $40 \mathrm{~cm}$. A análise dos resultados permitiu concluir que a textura argilosa pode ser considerada como fator determinante para dificultar as perdas de $\mathrm{C}$ orgânico. Freitas et al. (2000) ressaltaram o papel da argila na estruturação do solo e na proteção da MOS contra a decomposição em sistemas que apresentem ausência de revolvimento.

Tabela 6: Coeficiente de correlação dos estoques de carbono do cerrado (CER), pastagem melhorada (PME) e pastagem degrada (PDE) com a densidade, areia grossa, areia fina, silte e argila às profundidades 0 a 20 e 20 a $40 \mathrm{~cm}$.

\begin{tabular}{ccccccc}
\hline $\begin{array}{c}\text { Teor } \\
\text { carbono }\end{array}$ & $\begin{array}{c}\text { Profundidade } \\
(\mathbf{c m})\end{array}$ & Densidade & $\begin{array}{c}\text { Areia Grossa } \\
\left(\mathbf{g ~ k g}^{-1}\right)\end{array}$ & $\begin{array}{c}\text { Areia fina } \\
\left(\mathbf{g ~ k g}^{-1}\right)\end{array}$ & $\begin{array}{c}\text { Silte } \\
\left(\mathbf{g ~ k g}^{-1}\right)\end{array}$ & $\begin{array}{c}\text { Argila } \\
\left(\mathbf{g ~ k g}^{-1}\right)\end{array}$ \\
\hline \multirow{2}{*}{ CER } & $0-20$ & $-0,701440$ & $-0,958120$ & $-0,624420$ & 0,551897 & 0,956845 \\
& $20-40$ & $-0,756930$ & $-0,640460$ & $-0,029990$ & 0,160321 & 0,401332 \\
\hline \multirow{2}{*}{ PME } & $0-20$ & $-0,869280$ & $-0,483040$ & $-0,940290$ & 0,807998 & 0,752373 \\
& $20-40$ & $-0,338730$ & $-0,306140$ & $-0,788410$ & 0,630112 & 0,630112 \\
\hline \multirow{2}{*}{ PDE } & $0-20$ & $-0,755780$ & $-0,634490$ & $-0,287890$ & 0,283569 & 0,571925 \\
& $20-40$ & $-0,328590$ & $-0,499720$ & $-0,247730$ & 0,475294 & 0,405137 \\
\hline
\end{tabular}

Org. dos autores.

Soc. \& Nat., Uberlândia, ano 24 n. 2, 359-376, mai/ago. 2012 
Nas áreas de CER constatou-se uma correlação altamente positiva entre o estoque de $\mathrm{C}$ e os teores de argila na profundidade $0-20 \mathrm{~cm}$. Com relação à densidade, esta foi alta e negativamente correlacionada com o estoque de $\mathrm{C}$, ou seja, as variáveis são inversamente proporcionais, à medida que ocorre o aumento no estoque de $\mathrm{C}$, a densidade diminui nas duas profundidades de análise. Este é o comportamento esperado da densidade, quando correlacionada ao estoque de C. Nas áreas ocupadas pela PME e PDE, a densidade e o carbono estão negativamente correlacionados $(-0,869280$ e $-0,755780$, respectivamente para $0-20 \mathrm{~cm})$.

De forma geral verificou-se uma correlação positiva entre o estoque de carbono no solo e a quantidade de argila para as amostras de CER e PME analisadas. Esta evidência é mais marcante no cerrado do que nas áreas de pastagem pode ser explicada por outras variáveis que interferem no estoque de $\mathrm{C}$, como por exemplo, o estágio de degradação e ausência de manejo das mesmas.

\section{CONSIDERAÇÕES FINAIS}

Os resultados da pesquisa mostraram que as pastagens cultivadas e bem manejadas podem manter o nível do estoque de carbono nas camadas superficiais (0 a $20 \mathrm{~cm}$ ), equivalente ou superior ao estoque sob vegetação natural, especialmente o cerrado.

$\mathrm{Na}$ camada de solo de 0 a $20 \mathrm{~cm}$, a pastagem melhorada (Brachiaria) estocou no solo um total de 43,92 $\mathrm{Mg} \mathrm{C} \mathrm{ha}^{-1}$, enquanto o cerrado 38,05 $\mathrm{Mg} \mathrm{C} \mathrm{ha}^{-1}$ e a pastagem degradada $34,63 \mathrm{Mg} \mathrm{C}$ $\mathrm{ha}^{-1}$, enquanto que à profundidade $20 \mathrm{a} 40 \mathrm{~cm}, \mathrm{a}$ pastagem melhorada atingiu $33,5 \mathrm{Mg} \mathrm{C}^{-1}$, o cerrado $26,80 \mathrm{Mg} \mathrm{C} \mathrm{ha}^{-1}$ e a pastagem degradada 27,51 Mg C ha-1, esses dados demonstram que pastagens bem formadas e manejadas, podem contribuir no aumento da taxa de sequestro de carbono pelo solo. Entretanto, a má formação das pastagens, a falta de reposição de nutrientes no solo, o manejo inadequado, o excesso de lotação (sobrepastejo) tem levado degradação das pastagens cultivadas, o que compromete a capacidade das mesmas de seqüestrar carbono.
Observou-se que o teor de argila presente nos solos das amostras de CER possui correlação muito alta $(0,956845)$ com o estoque de $\mathrm{C}$ à profundidade $0-20 \mathrm{~cm}$. No que diz respeito à $\mathrm{PME}$, o índice de correlação é alto $(0,752373)$ em $0-20 \mathrm{~cm}$, ao passo que na PDE a correlação é moderada $(0,571925)$ nesta profundidade.

É possível concluir que a pastagem melhorada, com alta produtividade e bem manejada atua como seqüestrador de carbono, enquanto a pastagem degradada como emissor de carbono, quando comparada com a vegetação nativa de cerrado. O Brasil é um grande exportador no campo do agronegócio, por outro lado, a agricultura e a pecuária são os responsáveis por grande parte das emissões de gases de efeito estufa no país. Em função disso, o governo brasileiro passou a adotar metas de redução das emissões de carbono e a investir em programas e políticas de incentivo ao sequestro de carbono. O sequestro pode se dar através da intensificação do uso das terras, especialmente nas áreas de pecuária. Portanto, tais dados podem colaborar nas políticas governamentais, incentivando a adoção de técnicas como a integração Lavoura-Pecuária e integração Lavoura-Pecuária-Floresta que, além de contribuírem com a conservação ambiental, podem ser lucrativas para o produtor.

\section{AGRADECIMENTOS}

A Fundação de Amparo à Pesquisas do Estado de Minas Gerais (FAPEMIG) pelo financiamento da pesquisa.

\section{REFERÊNCIAS}

IPCC. 2007. Cambio Climático 2007: Mitigacíon del Cambio Climático. Contribución del Grupo de Trabajo III al Cuarto Informe de Evaluación del Grupo Intergubernamental de Expertos sobre Cambio Climático. Resumén Tecnico. Disponível em: < http://www.ipcc. $\mathrm{ch} /$ publications_and_data/publications_ipcc_fourth_assessment_report_wg3_report_mitigation_of_climate_change.htm >. Acesso em 8 jul 2008. 
BODDEY, R. M.; ALVES, B. J. R.; OLIVEIRA, O. C. de; URGUIAGA, S. Potencial para Acumulação e Sequestro de Carbono em Pastagens Brachiaria. In: LIMA, M. A.; CABRAL, O. M. R.; MIGUEZ, J. D. G. Mudanças Climáticas Globais e a Agropecuária Brasileira. EMBRAPA Meio Ambiente, Jaguariúna, SP, 2001, p. 213-229.

CERRI, C. C.; BERNOUX, M.; CERRI, C. E. P.; LAL, R. Challenges and Opportunities of Soil Carbon Sequestration in Latin America. In: LAL, R.; CERRI, C. C.; BERNOUX, M.; ETCHEVERS, J.; CERRI, E. Carbon Sequestration in Soils of Latin America. Haworth Press, 2006, p. 41-48.

CERRI, C. C.; CERRI, C. E. P. Agricultura e Aquecimento Global. 2007, 9 p. Disponível em: http:// www.aquecimento.cnpm.embrapa.br/bibliografia/ agr_e_aquec_Cerri_2007.pdf. Acesso em: 07 ago 2008.

EMBRAPA. Empresa Brasileira de Pesquisa Agropecuária. Sequestro de Carbono em Solos Sob Sistemas Agropecuários Produtivos. Embrapa Agrobiologia. Seropédica, RJ, 2004, 2p. Equipe do projeto BODDEY, R.; ALVES, B. J. R., URQUIAGA, S. S. Disponível em: < http://www.cnpab.embrapa.br/pesquisas/ folders/folder_sequestro_carbono.pdf $>$ Acesso em: 27 jul 2008.

CORAZZA, E. J.; SILVA, J. E.; RESCK, D. V. S.;GOMES, A. C. Comportamento de diferentes sistemas de manejo como fonte de depósito de carbono em relação à vegetação de cerrado. Revista Brasileira de Ciência do Solo, Viçosa, v. 23, n. 2, p. 425-432, 1999. Disponível em: < http://sbcs.solos.ufv.br/solos/revistas/ v23n2a25.pdf>. Acesso em: 15 ago 2007.

D’ ANDRÉA, A. F.; SILVA, M. L. N.; CURI, N.; GUILHERME. L.R. G. Estoque de carbono e nitrogênio e formas de nitrogênio mineral em um solo submetido a diferentes sistemas de manejo. Pesquisa Agropecuária Brasileira, Brasília, v.39, n.2, p.179186, 2004. Disponível em: <http://www.scielo.br/pdf/ pab/v39n2/19853.pdf>. Acesso: 10 mar 2008.
DIAS FILHO, M. B. Competição e sucessão vegetal em pastagens. $2^{\circ}$ Simpósio sobre manejo estratégico de pastagem. Viçosa: UFV; 2004 , p. 251-287.

FAO. Food and Agriculture Organization. Review of Evidence on Drylands Pastoral Systems and Climate Change: Implications and Opportunities for Mitigation and Adaptation. Roma, 2009. Disponível em: < http://ftp.fao.org/docrep/fao/012/i1135e/i1135e00. pdf $>$. Acesso em janeiro de 2010.

FREITAS, P. L.; BLANCANEAUX, F.; GAVINELLI, E.; LARRÉ-LARROUY, M.C; FELLER, C. Nível e natureza do estoque orgânico de Latossolos sob diferentes sistemas de uso e manejo. Pesquisa agropecuária brasileira, Brasília, v.35, n.1, p.157-170, 2000.

LIMA, M. A.; BOEIRA, R. C.; CASTRO, V. L. S. S.; LIGO, M. A. V.; CABRAL, O. M. R.; VIEIRA, R. F.; LUIZ, A. J. B. Estimativa das Emissões de Gases de Efeito Estufa Provenientes de Atividades Agrícolas no Brasil. In: LIMA, M. A.; CABRAL, O. M. R.; MIGUEZ, J. D. G. Mudanças Climáticas Globais e a Agropecuária Brasileira. EMBRAPA Meio Ambiente, Jaguariúna, SP, 2001, p. 169-189. p.193.

MIELNICZUCK, J. Matéria orgânica e a sustentabilidade de sistemas agrícolas. In: SANTOS, G. A; SILVA, L. S.; CANNELAS, L. P.; CAMARGO, F. O. Fundamentos da matéria orgânica do solo. Ecossistemas Tropicais e Subtropicais. $2^{\mathrm{a}}$ Ed. Metrópole, Porto Alegre, 2008, p. 1-4.

NEVES, C. M. N; SILVA, M. L. N.; CURI, N.; MACEDO, R. L. G; TOKURA, A. M. Estoque de Carbono em Sistemas Agrosilvopastoril, Pastagem e Eucaliptus sob cultivo convencional na região noroeste do estado de Minas Gerais. Ciênc. agrotec., Lavras, v. 28, n. 5, p. 1038-1046, set.out., 2004.

RANGEL, O. J. P.; SILVA, C. A. Estoques de Carbono e Nitrogênio e frações orgânicas de Latossolo submetido a diferentes sistemas de uso e manejo. Revista Brasileira de Ciencia do Solo, 31:1609-1623, 2007.

Soc. \& Nat., Uberlândia, ano 24 n. 2, 359-376, mai/ago. 2012 
ROSA, R. et al. Elaboração de uma base cartográfica e criação de um banco de dados georreferenciados da bacia do rio Araguari - MG. In: LIMA, S. do C., SANTOS, R. J. (Org.). Gestão Ambiental da Bacia do Rio Araguari Rumo ao desenvolvimento sustentável. Uberlândia, IG-UFU; Brasília: CNPq, 2004. p. $69-87$.

ROSENDO, J. S. Estoque de carbono nos solos da bacia do Rio Araguari-MG: estimativas, modelagem e cenários. 311 p. Tese (Doutorado em Geografia) - Universidade Federal de Uberlândia, Uberlândia. 2010. Disponível em:<http://www.ig.ufu.br/sites/ig.ufu.br/ files/Anexos/Bookpage/Jussara_Rosendo.pdf $>$.

SANO, E. E.; ROSA, R.; BRITO, J. L. S.; FERREIRA, L. G. Mapeamento do Uso do Solo e Cobertura Vegetal - Bioma Cerrado - Ano Base 2002. MMA/ SBF, Brasília, 2010.

TRUMBORE, S. E.; TORN, M. S. Soils and the Global Carbon Cycle. In: Soils and Global Change, EA Holland, ed. NATO Advanced Study Institute; LBNL-44910, 2003, p. 1-34.

YEOMANS, J.C.; BREMNER, J.M. A rapid and precise method for routine determination of organic carbon in soil. Comm. Soil Science Plant Anal., 19:1467-1476, 1988. 